\title{
DNA Degradation in Wild-type and Repair-deficient Strains of Salmonella typhimurium Exposed to Ultraviolet Light or Photodynamic Treatment
}

\author{
By R. ZIEBELL, F. PAULA IMRAY AND D. G. MACPHEE \\ Department of Genetics, La Trobe University, Bundoora, Victoria, \\ Australia 3083
}

(Received I I February I 977)

\begin{abstract}
Five mutants of Salmonella typhimurium strain LT2 $\operatorname{trpDI}(\mathrm{ColEI})^{+}$, initially detected because they released little or no colicin when tested on solid medium, proved to be sensitive to ultraviolet light (u.v.). Further testing indicated that one of the mutants was deficient in genetic recombination and was probably a rec $A$-type mutant, while three of the others were deficient in DNA polymerase activity and appeared to be typical polA mutants. The fifth mutant was less sensitive than the others to methyl methanesulphonate, showed reduced proficiency in genetic recombination, and was of approximately normal u.v. mutability. This mutant may be a counterpart of the class known as uvrD in Escherichia coli. All five mutants degraded significantly more of their DNA following exposure to u.v. than did the wild-type strain. The recA-type mutant and the possible $u v r D$ mutant also degraded significantly more of their DNA spontaneously than did the wild-type. Treatment with visible light and acridine orange (photodynamic treatment) caused no significant degradation of DNA in the wild-type strain, a highly significant increase in the extent of DNA degradation in a polA mutant, and a decrease in the extent of degradation in the recA-type mutant.
\end{abstract}

\section{INTRODUCTION}

Strains of Escherichia coli deficient in genetic recombination as a result of mutation of the $\operatorname{rec} A$ gene show increased sensitivity to ultraviolet light (u.v.) and an increased tendency to degrade their own DNA either spontaneously or following exposure to ultraviolet light (Howard-Flanders \& Boyce, 1966). Similarly, strains of $E$. coli deficient in the enzyme DNA polymerase $I$ as a result of mutation of the polA gene show increased sensitivity to ultraviolet light and an increased tendency to degrade their own DNA following exposure to ultraviolet light (de Lucia \& Cairns, I969; Boyle, Paterson \& Setlow, I970). In both cases, DNA degradation is thought to be the result of the activity of exonuclease $V$ coded for by the $\mathrm{recB} / \mathrm{recC}$ genes (Willetts \& Clark, 1969; Youngs \& Bernstein, I973). Mutants of Salmonella typhimurium which closely resemble recA and polA mutants of $E$. coli in a number of properties have previously been described (MacPhee, 1970; MacPhee \& Beazer, 1973, 1975). This paper describes the isolation of further mutants of the rec $A$ and polA types in $S$. typhimurium, and reports that excessive DNA degradation following exposure to u.v. is another property which they share with their $E$. coli counterparts. After treatment with acridine orange plus visible light (photodynamic treatment), the $\operatorname{rec} A$-type mutants actually degrade less DNA than they do spontaneously, whereas polA mutants degrade significantly more. 


\section{METHODS}

Bacterial strains. All strains used were derived from DG722, which is $S$. typhimurium LT2 trpDI gal. Strain DG767 is a derivative of DG722 given the colicin factor ColEI-30 by conjugation with an F' $^{\prime}$ al $^{+}$ $(\mathrm{ColEI})^{+}$donor. In constructing strain DG767, selection was made initially for $\mathrm{Gal}^{+}$transconjugants, about $20 \%$ of which also acquired the ColEI plasmid presumably as a result of mobilization by the $\mathrm{F}^{\prime}$ gal plasmid. One of the $\mathrm{Gal}^{+}(\mathrm{ColEI})^{+}$transconjugants was then purified by replating twice on the medium used for selection, and a spontaneous $\mathrm{Gal}^{-}$segregant was obtained by repeated restreaking on EMB-galactose medium. Strain DG767 is therefore LT2 trpDI gal (ColEI) ${ }^{+}$. The repair deficient mutants DG958, DG96o, DG962, DG964 and DG966 were detected after $N$-methyl- $N^{\prime}$-nitro- $N$-nitrosoguanidine (NTG) mutagenesis of strain DG767 as clones which were unable to release colicin EI and which were also u.v. sensitive (MacPhee, 1970).

Media. The principal liquid medium used was Davis minimal medium supplemented with casein amino acids (minimal-CAA medium). The composition of the basic medium was $\left(\mathrm{gl}^{-1}\right): \mathrm{K}_{2} \mathrm{HPO}_{4}, 6 ; \mathrm{KH}_{2} \mathrm{PO}_{4}, 2$; $\left(\mathrm{NH}_{4}\right)_{2} \mathrm{SO}_{4}, \mathrm{I} ; \mathrm{MgSO}_{4} .7 \mathrm{H}_{2} \mathrm{O}, 0 . \mathrm{I}$. Glycerol $(0.2 \%, \mathrm{v} / \mathrm{v})$ and casein amino acids (Calbiochem; $0.2 \%$, w/w) were added as required. Other media have been described previously (MacPhee, 1970, 1973).

Characterization of mutants releasing little or no colicin. All methods used for characterizing these mutants as either recA-type or polA-type have been described previously (MacPhee, 1970; MacPhee \& Beazer, 1973, 1975).

Ultraviolet irradiation. Bacteria to be irradiated were suspended in Davis minimal medium and exposed to a Philips bactericidal lamp delivering about $\mathrm{I} \cdot 6 \times \mathrm{I}^{-6} \mathrm{~J} \mathrm{~mm}^{-2} \mathrm{~s}^{-1}$ at the distance used for irradiation. The suspensions were stirred mechanically during irradiation.

Photodynamic treatment. Bacteria suspended in minimal-CAA medium were sensitized by shaking in the dark with acridine orange $\left(30 \mu \mathrm{g} \mathrm{ml}^{-1}\right)$ at $0^{\circ} \mathrm{C}$ for $30 \mathrm{~min}$. The samples were then exposed to a visible light source (500 W Philips Photoflood bulb) for 3 min as described previously (Imray \& MacPhee, 1973). Dark controls were treated with acridine orange but not exposed to light. Light controls were exposed to light without pretreatment with acridine orange.

Measurement of DNA degradation. An $18 \mathrm{~h}$ broth culture of the strain to be tested was diluted Io-fold into minimal-CAA medium and incubated at $37^{\circ} \mathrm{C}$ for $18 \mathrm{~h}$ with shaking. The resulting culture was diluted I: 100 into fresh minimal-CAA medium containing $4 \mu \mathrm{Ci}\left[{ }^{3} \mathrm{H}\right]$ thymidine $\mathrm{ml}^{-1}$ together with deoxyadenosine $\left(250 \mu \mathrm{g} \mathrm{ml}^{-1}\right)$ to stimulate the incorporation of exogenous thymidine. After overnight incubation with shaking at $37^{\circ} \mathrm{C}$, the bacteria were collected on a membrane filter (Millipore, $0.45 \mu \mathrm{m}$ pore size) and washed twice with minimal medium. The washed bacteria were resuspended in fresh minimal-CAA medium, and incubated at $37^{\circ} \mathrm{C}$ for $90 \mathrm{~min}$ to exhaust the intracellular thymidine pool. The bacteria were again collected on a membrane filter, washed twice with minimal medium, and resuspended in minimal-CAA medium. Samples from this bacterial suspension were used as control or treated cultures. Following the appropriate treatment, samples were diluted $\mathrm{I}: 20$ in minimal-CAA medium and shaken at $37^{\circ} \mathrm{C}$ for either 2 or $4 \mathrm{~h}$. During this time, $0.5 \mathrm{ml}$ samples were taken at intervals and mixed with I ml of cold $10 \%$ (w/v) trichloroacetic acid (TCA). A sample taken immediately after treatment was mixed with $\mathrm{I} \mathrm{ml}$ of $10 \% \mathrm{TCA}$ and hydrolysed by heating at $85^{\circ} \mathrm{C}$ for $90 \mathrm{~min}$. A $0.5 \mathrm{ml}$ sample of this hydrolysed mixture was placed in scintillation fluid and the radioactivity was assayed to give a measure of the total amount of $\left[{ }^{3} \mathrm{H}\right]$ thymidine present at zero time. The other samples were kept at $0^{\circ} \mathrm{C}$ until the last one had been taken, and then human serum albumin [ $0.1 \mathrm{ml}$ of a $\mathrm{I} \%(\mathrm{w} / \mathrm{v})$ solution] was added to each sample as a carrier before centrifuging at $3000 \mathrm{~g}$ for $30 \mathrm{~min}$. From the supernatant fluids, $0.5 \mathrm{ml}$ samples were taken and added to $10 \mathrm{ml}$ scintillation fluid for counting. The scintillation fluid consisted of: toluene, $750 \mathrm{ml}$; Triton-X (Rohm \& Haas Co., Philadelphia, U.S.A.), $250 \mathrm{ml}$; 2.5-diphenyloxazole (Packard Instrument Co., Illinois, U.S.A), $6 \mathrm{~g}$; and I,4-di-2-(4-methyl-5-phenyloxazolyl)benzene (Packard Instrument Co.), 0.3 g.

\section{RESULTS}

\section{Isolation and characterization of the repair-deficient mutants}

The inability to release colicin Er can be used as a screening technique to facilitate identification of rec $A$ and polA mutants among the survivors of a mutagenized culture (MacPhee, 1970; MacPhee \& Beazer, 1973). A total of 4760 survivors of NTG treatment of a culture of strain DG767 were tested for colicin EI release as described previously (MacPhee \& Beazer, 1973). Eight clones which produced either no detectable colicin or only very small amounts were purified and tested for their sensitivity to u.v. Five of the eight 
Table I. Summary of properties of five mutants of S. typhimurium strain $\mathrm{DG} 767$ isolated on the basis of their failure to release colicin $\mathrm{EI}$

\begin{tabular}{|c|c|c|c|c|c|c|}
\hline \multirow[b]{2}{*}{ Property } & \multicolumn{6}{|c|}{ Strain } \\
\hline & DG 767 & DG958 & DG960 & DG962 & DG964 & DG966 \\
\hline U.v. resistance & $\mathrm{R}$ & s & ss & s & $\mathbf{s}$ & $\mathbf{s}$ \\
\hline MMS resistance & $\mathrm{R}$ & ss & SS & SS & ss & $\mathbf{S}$ \\
\hline Recombination proficiency & $++t$ & +++ & 0 & +++ & $++t$ & + \\
\hline Phage release by lysogens & + & ++ & 0 & ++ & ++ & ++ \\
\hline Colicin EI release & ++ & 0 & + & o & 0 & + \\
\hline Host-cell reactivation ability & +++ & + & +++ & + & + & + \\
\hline DNA degradation (spontaneous) & + & + & ++ & + & + & ++ \\
\hline DNA degradation (after u.v.) & + & +++ & +++ & +++ & +++ & +++ \\
\hline U.v. mutability* & ++ & + & 0 & + & + & ++ \\
\hline $\begin{array}{l}\text { DNA polymerase enzyme assay } \\
\text { Likely genotype }\end{array}$ & $\begin{array}{l}+++ \\
\text { w.t. }\end{array}$ & $\begin{array}{l}\circ \\
\text { polA }\end{array}$ & $\begin{array}{c}+++ \\
\operatorname{rec} A\end{array}$ & $\begin{array}{c}\circ \\
\text { polA }\end{array}$ & $\begin{array}{c}+ \\
\text { polA }\end{array}$ & $\begin{array}{c}+++ \\
u v r D\end{array}$ \\
\hline
\end{tabular}

$\mathrm{R}$, Resistant; s, sensitive; ss, very sensitive.

*Assessed by measuring back mutation to prototrophy of the trpDr marker.

clones showed an increased sensitivity to u.v. and were thought likely to be mutant at either recA or polA. The main characteristics of these five strains were determined as described previously (MacPhee \& Beazer, I973), and are shown in Table I.

Strains DG958, DG962 and DG964 have all of the properties of the polA derivatives isolated in the FIRN line of $S$. typhimurium by MacPhee \& Beazer (1973, I975), except that DG964 retains about $25 \%$ of the ability of wild-type strains to polymerize DNA in a crude assay system. The mutation conferring sensitivity to methyl methanesulphonate (MMS) in strain DG962 is cotransduced by phage PI with $r h a$ at a frequency of about $8 \%$, as are the polA mutations previously described in both $S$. typhimurium and $E$. coli. The mutation in strain DG962 has therefore been designated polA5. Strain DG960 resembles the rec $A$-type mutants of the FIRN line described by MacPhee (1970) in almost all properties tested, and is clearly also a rec $A$-type mutant (designated rec-364, since the mutation has not yet been mapped). Strain DG966 differs from all other u.v.- and MMS-sensitive mutants isolated on the basis of their failure to release colicin Er by being neither deficient in DNA polymerase nor fully deficient in genetic recombination. It is, however, u.v. mutable, deficient in the capacity to effect host-cell reactivation of u.v.-irradiated bacteriophage ESI 8, capable of releasing phage when made lysogenic, and somewhat deficient in recombination, as judged by the frequency of P22-mediated transduction.

\section{U.v.-induced DNA degradation}

Strains DG767, DG722 (which is strain DG767 without the ColEI plasmid), and the five radiation-sensitive mutants described above, were tested for their capacity to release TCAsoluble material following a u.v. dose of about $5 \times \mathrm{IO}^{-5} \mathrm{~J} \mathrm{~mm}^{-2}$. Representative results a re shown in Fig. I. The wild-type strain DG767 had a very low level of both spontaneous and u.v.-induced DNA degradation, as did the non-colicinogenic strain DG722 (not shown). The polA5 mutant (strain DG962) responded somewhat differently, since although spontaneous DNA degradation was low, degradation following u.v. treatment was extensive, releasing between 30 and $40 \%$ of its genome as acid-soluble material within an hour. The other two polA-type mutants (DG958 and DG964) gave results similar to those of DG962. The results for DG960 were similar to those obtained by Wing, Levine \& Smith (1968) with a $\mathrm{Rec}^{-}$mutant of $S$. typhimurium which also appears to be $r e c A$-type.

The fifth mutant, strain DG966, also showed an increased tendency to break down DNA spontaneously, and although its response to u.v. was less extreme than that of the $\operatorname{rec} A$ - 

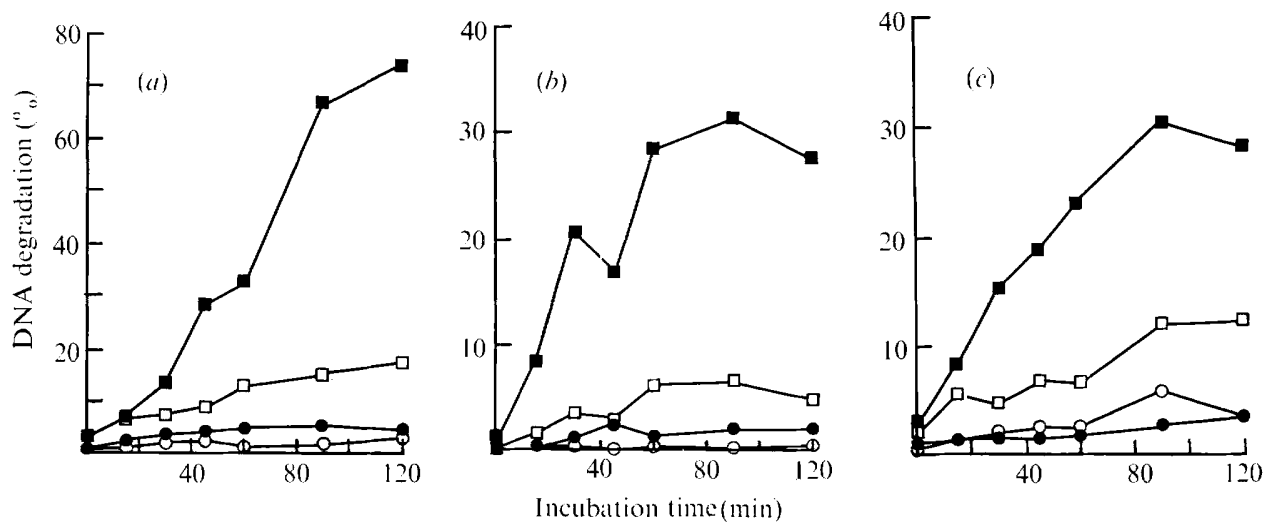

Fig. I. DNA degradation induced by the same u.v. dose (about $5 \times 10^{-5} \mathrm{~J} \mathrm{~mm}^{-2}$ ) in wild-type and repair-deficient strains of $S$. typhimurium. (a) DG960 (recA-type) with (⿴) and without ( $\square$ ) u.v. DG767 (wild-type) with $(\bullet)$ and without $(\bigcirc)$ u.v. $(b)$ DG962 (polA-type) with (ロ) and without $(\bullet)$ u.v. DG767 (wild-type) with $(\square)$ and without $(\bigcirc)$ u.v. (c) DG966 (possible uvrD mutant) with (汭) and without $(\square)$ u.v. DG767 (wild-type) with $(\bigcirc)$ and without $(\bullet)$ u.v.

type mutant, nonetheless about $30 \%$ of its genome had been released as acid-soluble material within $100 \mathrm{~min}$ of treatment.

\section{Photodynamically-induced DNA degradation}

The results of measuring the release of ${ }^{3} \mathrm{H}$-labelled material into the acid-soluble fraction following acridine orange-sensitized photodynamic treatment of strains DG722 (wild-type), DG962 (polA) and DG960 (recA-type) are shown in Fig. 2. There was very little DNA breakdown in the wild-type strain whether it was exposed to photodynamic treatment or not. On the other hand photodynamic treatment of the polA strain led to extensive DNA breakdown, while even treatment with visible light or acridine orange alone led to a significant breakdown of DNA. The recA-type strain DG960 had a relatively high level of spontaneous degradation of its DNA. This level was increased by treatment with either visible light or acridine orange alone, but, unexpectedly, there was a decrease in the level of DNA breakdown after the full photodynamic treatment - especially in comparison with the light and dark control results.

\section{DISCUSSION}

Four of the five mutants in the LT2 subline of $S$. typhimurium, isolated because they failed to release significant amounts of colicin EI, closely resemble mutants previously isolated in the FIRN subline (MacPhee, 1970: MacPhee \& Beazer, 1973, 1975). Three of the LT2 mutants are deficient in DNA polymerizing activity as judged by assays of crude extracts and appear similar in all other properties tested. These mutants are almost certainly polA mutants, although only one of them ( $\mathrm{polA5}$ ) has been mapped. Another of the mutants (rec-364; DG960) appears to be totally deficient in genetic recombination and, because it resembles the rec $A$-type mutants previously described in all tested properties, has also been designated 'recA-type'. The fifth mutant (DG966) differs from polA mutants in showing reduced recombination ability, in retaining some ability to release colicin EI (polA mutants are thought to be unable to maintain the ColEr plasmid, and hence would not be expected to release any colicin at all), in retaining essentially wild-type levels of u.v. mutability, and in showing both enhanced spontaneous and enhanced radiation-induced DNA degradation. Mutant DG966 differs from the recA-type mutants in a number of respects, including the fact that it is less sensitive to u.v., that it has reduced ability to effect host-cell reactivation 


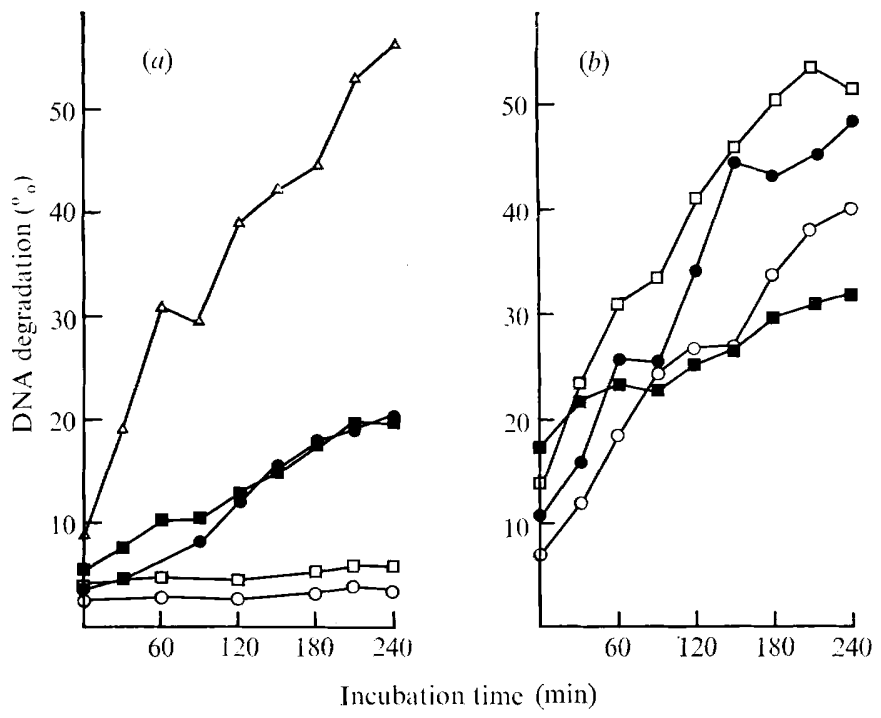

Fig. 2. DNA degradation induced by photodynamic treatment of wild-type and repair-deficient strains of $S$. typhimurium. (a) DG722 (wild-type): $\bigcirc$, without acridine orange or light treatment; $\square$, after photodynamic treatment. DG962 (polA-type): $O$, after treatment with visible light alone; $\mathbf{\square}$, after treatment with acridine orange alone; $\triangle$, after full photodynamic treatment. (b) DG96o (rec $A$-type): $\bigcirc$, without acridine orange or light treatment; $O$, after treatment with visible light alone; $\square$, after treatment with acridine orange alone; $\square$, after full photodynamic treatment.

of u.v.-irradiated bacteriophage ESI 8, and that lysogenic derivatives of it release free phage at normal or even elevated rates. Mutants of $E$. coli which share many of the properties of strain DG966, including u.v. sensitivity, spontaneous release of phage from lysogens, and slightly reduced recombination ability, have been described by Ogawa, Shimida \& Tomizawa (1968) and Ogawa (1970) and designated uvrD. Such mutants also resemble strain DG966 in showing an increased tendency to degrade their own DNA both spontaneously and after u.v. treatment (Youngs \& Bernstein, 1973). In $E$. coli, several different $u v r D$ mutations are closely linked to the metE gene (Ogawa et al., 1968; Ogawa, 1970) and it is therefore of interest that the mutation conferring u.v. and MMS sensitivity on strain DG966 can be cotransduced with the Salmonella metE gene by phage Pi (see MacPhee \& Beazer, 1975, for methods) at a frequency of about $10 \%$. In view of the above similarities, it seems likely that strain DG966 is mutant in a gene equivalent to the $u v r D$ gene of $E$. coli. However, the property which led to strain DG966 being isolated is not one which is shared by the two $u v r D$ mutants of $E$. coli so far tested, both of which appear to release colicin EI quite normally (MacPhee, unpublished observation). This may simply reflect differences in the behaviour of different alleles, but we cannot exclude the possibility that strain DG966 contains a second mutation responsible for reduced colicin release in addition to the $u v r D$ type mutation - especially in view of the fact that strain DG966 was isolated following NTG treatment, which often leads to second site mutations being introduced (Guerola, Ingraham \& Cerdá-Olmedo, I97I).

The low spontaneous levels and relatively high (30 to $40 \%$ ) u.v.-induced levels of DNA degradation shown by strains DG958, DG962 and DG964 provide further evidence that all three are polA mutants, closely resembling certain polA mutants of $E$. coli in this as in all other important respects. Similarly, the increased levels of both spontaneous and u.v.induced $(>70 \%$ ) DNA degradation shown by strain DG960 serve as further evidence that the 'recA-type' mutants of $S$. typhimurium so far described are the counterparts of rec $A$ mutants of $E$. coli. 
Photodynamic treatment produces no significant DNA degradation in the wild-type strain DG722, which also shows a low level of spontaneous DNA degradation. The rec-364 mutant (DG960) shows a high level of DNA degradation both spontaneously and when treated with visible light or acridine orange alone (Fig. $2 b$ ). However, after photodynamic treatment strain DG960 degrades its DNA to a lesser extent than is found in either the light or dark controls. Explanations for the apparent inhibition of DNA degradation after photodynamic treatment could involve damage to protein or modification of the DNA making it resistant to nuclease attack. Photodynamic treatment can destroy enzyme activity (Spikes \& Livingstone, 1969), but it seems unlikely that such treatment destroys nucleases responsible for DNA degradation since the polA5 mutant DG962 shows extensive DNA degradation after the same photodynamic treatment (Fig. 2a). Photodynamic treatment can also cause cross-linking of DNA to protein (Smith, 1962) resulting in a decrease in extractivity of DNA and can markedly decrease the sensitivity of DNA to enzymic degradation (Dellweg \& Opree, 1966). Again, however, the extensive DNA degradation in the polA strain argues against any simple hypothesis involving a modification of DNA structure by photodynamic treatment making it resistant to nuclease attack. Other explanations for the fact that photodynamic treatment does not induce DNA degradation in recA bacteria, although they are sensitive to photodynamic killing (Imray \& MacPhee, 1973), could involve the type of lesion caused by photodynamic action. One possibility is that replication past the lesion induced by photodynamic treatment may not lead to singlestrand gaps (assuming a single-strand break or gap is necessary for initiation of DNA degradation), or, alternatively, there may be no post-replication repair of photodynamic damage, i.e. the lesion is lethal if it is replicated.

These results have an interesting parallel in a study of the effects of relatively high doses of visible and near ultraviolet light on $\operatorname{rec} A$ mutants of $S$. typhimurium (Ferron, Eisenstark \& Mackay, 1972). In that study, $\operatorname{rec} A$ bacteria were found to be significantly more sensitive to visible or near ultraviolet light, and yet there was no significant increase in DNA degradation. The parallels between visible light effects, near ultraviolet light effects and photodynamic effects suggest that an internal sensitizer may be involved.

Following photodynamic treatment, there is extensive DNA degradation in the polA5 strain (Fig. 2a). This suggests that photodynamic treatment leads to formation of singlestrand gaps (either directly or by excision of damaged bases) which in the wild-type strain are refilled by DNA polymerase I repair resynthesis, but which in the absence of DNA polymerase I cannot be efficiently filled and hence there is further DNA degradation. A similar explanation has been proposed for u.v.- and $\gamma$-induced DNA degradation in polA strains of $E$. coli, and it has been suggested that the nuclease responsible for this degradation is exonuclease V - the $\mathrm{rec} B / \mathrm{recC}$-coded nuclease (Youngs \& Bernstein, 1973).

This work was supported by grants from the Australian Research Grants Committee, and from the Australian Institute of Nuclear Science and Engineering. We are grateful to Miss R. Tunbridge and Mrs M. Leyden for expert technical assistance.

\section{REFERENCES}

Boyle, J. M., Paterson, M. C. \& Setlow, R. B. (1970). Excision repair properties of an Escherichia coli mutant deficient in DNA polymerase. Nature, London 266, 708-710

DellweG, H. \& OPReE, W. (I966). Die photodynamische Wirkung von Thiopyronin auf Nucleinsäuren. Biophysik 3, 24I-248.

Ferron, W. L., Eisenstark, A. \& Mackay, D. (1972). Distinction between far- and near-ultraviolet killing of recombinationless ( $r e c A$ ) Salmon- ella typhimurium. Biochimica et biophysica acta 227, $65 \mathrm{I}-658$.

Guerola, N., Ingraham, I. L. \& Cerdá-Olmedo, E. (I97I). Induction of closely linked multiple mutations by nitrosoguanidine. Nature New Biology 230, I22-1 25.

Howard-Flanders, P. \& Boyce, R. B. (1966). DNA repair and genetic recombination: studies on mutants of $E$. coli defective in these processes. Radiation Research Supp. 6, 156-184. 
Imray, F. P. \& MacPheE, D. G. (1973). The role of DNA polymerase I and the rec system in survival of bacteria and bacteriophages damaged by the photodynamic action of acridine orange. Molecular and General Genetics 123, 289-298.

DE LuCIA, P. \& CAIRNS, J. (I969). Isolation of an $E$. coli strain with a mutation affecting DNA polymerase. Nature, London 224, I I 64-I 66.

MACPheE, D. G. (1970). Recombination-deficient mutants of colicinogenic strains of Salmonella typhimurium detected by their failure to produce colicin. Journal of Bacteriology I04, 345-350.

MACPHeE, D. G. (1973). Effects of an R factor and caffeine on ultraviolet mutability in Salmonella typhimurium. Mutation Research 18, 367-370.

MacPhee, D. G. \& Beazer, M. R. (1973). Mutants of Salmonella typhimurium deficient in DNA polymerase I: detection by their failure to produce colicin EI. Molecular and General Genetics 127, 229-240.

MacPhee, D. G. \& Beazer, M. R. (1975). Mutants of Salmonella typhimurium deficient in DNA polymerase I : further characterization and genetic analysis. Australian Journal of Biological Sciences 28, 559-565.

OGaWA, H. (1970). Genetic locations of $u \mathrm{vrD}$ and pol genes of E. coli. Molecular and General Genetics 108, 378-381.
Ogawa, H., Shimida, K. \& Tomizawa, A. (1968). Studies on radiation-sensitive mutants of $E$. coli. I. Mutants defective in the repair synthesis。 Molecular and General Genetics ror, 227-244.

Smith, K. C. (1962). Dose dependent decrease in extractability of DNA from bacteria following irradiation with ultraviolet light or with visible light plus dye. Biochemical and Biophysical Research Communications 8, 157-163.

Spikes, J.D \& Livingstone, R. (1969). The molecular biology of photodynamic action: sensitized photautoxidations in biological systems. Advances in Radiation Biology 3, 29-121.

Willetts, N. S. \& Clark, A. J. (I969). Characteristics of some multiply recombination-deficient strains of E. coli. Journal of Bacteriology roo, 23 I -239.

Wing, J. P., Levine, M. \& Smith, H. O. (I968). Recombination-deficient mutant of Salmonella typhimurium. Journal of Bacteriology 95, I8281834 .

Youngs, D. A. \& Bernstein, I. A. (I973). Involvement of the recB-recC nuclease (exonuclease $\mathrm{V}$ ) in the process of X-ray induced deoxyribonucleic acid degradation in radiosensitive strains of Escherichia coli $\mathrm{K12}$. Journal of Bacteriology 113, 90I-906. 